\title{
HUBUNGAN INTENSITAS SUARA MESIN PENGGILINGAN PADI DENGAN KELUHAN GANGGUAN PENDENGARAN PEKERJA DI DESA KURIPAN KECAMATAN KESUGIHAN KABUPATEN CILACAP TAHUN 2015
}

\author{
Friandini Bayu Purwaningtyas ${ }^{1)}$, Djamaluddin Ramlan²) \\ Jurusan Kesehatan Lingkungan, Politeknik Kesehatan Kemenkes Semarang, \\ Jl.Raya Baturaden KM 12 Purwokerto, Indonesia
}

\begin{abstract}
Abstrak
Tenaga kerja mempunyai peranan yang penting sebagai penggerak roda pembangunan nasional khususnya yang berkaitan dengan sektor industri yang tidak luput dari resiko terjadi celaka dan penyakit sebagai akibat dari pekerjaan.Tujuan dari penelitian ini adalah untuk memperoleh gambaran hubungan intensitas suara mesin penggilingan padi dengan keluhan gangguan pendengaran pekerja. Metode penelitian yang digunakan adalah penelitian observasi analitik dengan pendekatan crossectional. Penelitian dilakukan di 3 lokasi penggilingan padi di desa kuripan kecamatan kesugihan kabupaten cilacap. Populasi dalam penelitian ini adalah semua pekerja pada penggilingan padi dengan total keseluruhan pekerja: 8 orang.Hasil dari penelitian ini diketahui terdapat 5 titik pengukuran yang tidak memenuhi syarat ( $>N A B=85 \mathrm{dBA}$ ). Titik $A_{1}$ sebesar $87.24 \mathrm{dBA}$, titik $A_{2}$ sebesar 91.6 dBA, titik $B_{4}$ sebesar 85.62 dBA, titik $C_{1}$ sebesar 92.17 dBA, titik $C_{2}$ sebesar 86.22 dBA. Jenis keluhan yang dialami pekerja pada 3 lokasi penggilingan padi yaitu berupa telinga berdenging, percakapan diulang, gangguan komunikasi dan keluhan pusing/sakit kepala.Simpulan dari penelitian ini adalah hasil uji statistik menggunakan korelasi range spearman's diperoleh hasil $p=0,223>\alpha(0,05)$, artinya tidak ada hubungan antara intensitas suara mesin penggilingan padi dengan keluhan gangguan pendengaran pekerja di Desa Kuripan Kecamatan Kesugihan Kabupaten Cilacap. Disarankan untuk penelitian lebih lanjut dilakukan penambahan jumlah responden.
\end{abstract}

Kata kunci : intensitas suara, keluhan gangguan pendengaran

\begin{abstract}
[Correlation between rice milling machine's noise intensity with workers hearing loss grievance in Kuripan sub-districts Kesugihan District Cilacap Regency Year of 2015]. Labor has an important role as national development initiator, especially in the industrial sector which cannot set apart from injury and disease as working side effect. The research objective was investigating the correlation between rice milling machine; noise intensity with workers hearing loss grievance. The research method used was observational analytic research with cross sectional approach. The research was conducted at three rice mill locations in Kuripan sub-districts Kesugihan District Cilacap Regency. The research populations were all workers so the total workers in Kuripan sub-districts Kesugihan District Cilacap Regency was 8 person. The research shows that there was five measurement points that did are not qualify the requirement (> NAB = $85 \mathrm{dBA}$ ). Point A1 was $87.24 \mathrm{dBA}$, point A2 was $91.6 \mathrm{dBA}$, point B4 was $85.62 \mathrm{dBA}$, point $C 1$ was $92.17 \mathrm{dBA}$, point $C 2$ was $86.22 \mathrm{dBA}$. The workers grievance type were ringing in the ears, repeated conversation, communication disorders and dizziness / headache. The conclusion drawn was; the statistical test result using Spearman's Rho correlation obtained $p=0.223>\alpha(0.05)$, that mean there is no significant correlation between the rice milling machine's noise intensity with workers hearing loss grievance in Kuripan sub-districts Kesugihan District Cilacap Regency. Future research expected adding the respondent number.
\end{abstract}

Keyword : Noise Intensity, Hearing Loss Greivance

\section{PENDAhuluan}

Tenaga kerja mempunyai peranan yang penting sebagai penggerak roda pembangunan nasional khususnya yang berkaitan dengan sektor industri yang tidak luput dari resiko terjadi celaka dan penyakit sebagai akibat dari pekerjaan mengingat pentingnya pekerja bagi produksi diperlukan perlindungan dan pemeliharaan kesehatan bagi

1) Email : friandini_bp@yahoo.com

2) Email : Djamaluddinramlan@gmail.com pekerja agar tercipta kondisi tempat kerja yang aman dan nyaman (A. M. Sugeng Budiono, 2003).

Upaya kesehatan kerja ditujukan untuk melindungi pekerja agar hidup sehat dari gangguan kesehatan serta pengaruh buruk yang diakibatkan oleh pekerjaan (UU no. 36 tahun 2006 pasal 164). Peraturan Menteri Tenaga Kerja dan Transmigrasi No. 01/1961 menyebutkan bahwa penyakit akibat 
kerja adalah setiap penyakit yang disebabkan oleh pekerjaan atau lingkungan kerja.Efek negatif tersebut bisa timbul dari penyakit akibat kerja yang ada dalam ruang/tempat kerja yang dibagi dalam 5 golongan yaitu golongan fisik, kimia, biologi, fisiologi dan mental psikologi. Produktivitas tenaga kerja menurun dikarenakan beberapa faktor antara lain: meja kursi tidak ergonomis, kebosanan dalam bekerja dan kelelahan dalam melakukan aktivitas pekerjaannya. (Suma'mur P.K, 1996).

Intensitas suara yang dihasilkan pada usaha penggilingan padi sangat ditentukan oleh musim penggilingan yang digunakan, jarak pekerja dengan sumber suara. Lama paparan dalam sehari kerja, masa kerja, sifat suara yang didengar dan intensitas suara yang didengar serta perlindungan diri saat ditempat kerja, misalnya saat bekerja menggunakan alat pelindung telinga yang benar. Hasil survey pendahuluan yang peneliti lakukan pada unit usaha penggilingan padi Dwi Tunggal, Tri Manunggal dan Rukun Tani Maju di Desa Kuripan Kecamatan Kesugihan Kabupaten Cilacap.Diketahui pekerja penggilingan padi berjumlah 8 orang dan yang merasakan gangguan telinga berupa pendengaran kurang sebanyak 3orang.Terdapat beberapa pekerja yang tidak menggunakan APD saat bekerja.Peneliti simpulkan intensitas suara dalam ruang penggilingan tinggi (berdasarkan pendengaran).Hal ini diketahui saat melakukan percakapan intensitas suara keras.Tujuan penelitian ini adalah untuk memperoleh gambaran hubungan intensitas suara mesin Penggilingan Padi dengan keluhan gangguan pendengaran pekerja di Desa Kuripan Kecamatan Kesugihan Kabupaten Cilacap.

\section{BAHAN DAN METODE}

Jenis penelitian yang digunakan adalah penelitian observasi analitik dengan pendekatan crossectional.

Populasi dalam penelitian ini adalah semua pekerja pada penggilingan padi Dwi Tunggal sebanyak: 2 orang, Tri Manunggal sebanyak: 3 orang, dan Rukun Tani Maju sebanyak: 3 orang dengan total keseluruhan pekerja yang berada Di Desa Kuripan, Kecamatan Kesugihan, Kabupaten Cilacap sebanyak: 8 orang. Sampel yang diambil dalam penelitian ini adalah total populasi:8 orang. Instrument yang digunakan pada penelitian ini diantaranya sebagai berikut : Sound Level Meter, meteran, kuesioner, checklist, dan alat tulis. Analisis menggunakan univariat dan bivariat. Untuk analisis bivariat menggunakan uji statistik korelasi range spearman's.

\section{III.HASIL DAN PEMBAHASAN}

Penelitian dilaksanakan selama 4 hari (tanggal 8 Juni- 11 Juni 2015) pada 3 lokasi peneliti yaitu di Industri Penggilingan Padi Dwi Tunggal merupakan lokasi A, Tri Manunggal merupakan lokasi B, Rukun Tani Maju merupakan lokasi C yang berada di Desa Kuripan, Kecamatan Kesugihan, Kabupaten Cilacap.
Proses produksi Ke-3 penggilingan padi dimulai pukul 08.00 sampai dengan 16.00 WIB. Waktu kerja berlaku sama untuk semua Industri Penggilingan Padi yang berada di Desa Kuripan Kecamatan Kesugihan Kabupaten Cilacap. Hari kerja Ke-3 industri penggilingan padi dilakukan selama 7 hari.

Proses penggilingan padi dari awal sampai akhir yaitu sistem penggilingan dimana proses padi menjadi beras dilakukan secara bertahap. Tahapan penggilingan padi sebagai berikut:

1. Penjemuran

Penjemuran dilakukan untuk mengeringkan padi agar terhindar dari pertumbuhan kapang yang dapat menyebabkan warna kuning. Pengeringan dapat dilakukan dengan memakai sinar matahari.

2. Pembersihan

Pembersihan gabah menggunakan ayakan sehingga dihasilkan gabah bersih.

3. Pemecahan Kulit

Alat yang digunakan adalah pemecah kulit tipe silinder, hasil pemecahan kulit adalah beras pecah kulit, sebagian kecil gabah utuh yang lolos.

4. Penyosohan

Alatnya adalah mesin penyosoh (rice polisher), karena ada gesekan antara beras dengan batu, lempengan karet, dan antara sesama beras maka beras akan tersosoh. Hasil penyosohan adalah beras sosoh, dedak, bekatul. Dedak dan bekatul langsung dipisahkan dengan aspirator.

Hasil penelitian terhadap 8 responden didapatkan pekerja yang memiliki masa kerja antara 1-6 tahun sebanyak 6 orang, dan masa kerja 7-12 tahun sebanyak 2 orang. Semakin lama seseorang bekerja pada tempat yang intensitas suaranya tinggi dan melebihi ambang batas maka akan semakin tinggi resiko terkena gangguan kesehatan, terutama gangguan pendengaran. Hasil wawancara didapat masa kerja yang paling lama yaitu 7-12 tahun dan yang baru yaitu 1-6 tahun, sehingga pekerja yang memiliki masa kerja 7-12 tahun lebih berisiko terkena gangguan kesehatan berupa gangguan pendengaran dari pada pekerja yang memiliki masa kerja 1-6 tahun.Proses produksi pada Industri Penggilingan Padi menggunakan mesin-mesin yang mempunyai fungsi dan jumlah yang berbeda. Mesin-mesin yang digunakan dalam proses produksi yaitu mesin peka yang berfungsi untuk membersihkan gabah dan mesin polister yang berfungsi untuk memecah gabah menjadi beras. Industri penggilingan padi Dwi Tunggal memiliki mesin peka sebanyak 2 unit dan mesin polister sebanyak 2 unit, Tri Manunggal memiliki mesin peka sebanyak 2 unit dan mesin polister sebanyak 2 unit, Rukun Tani Maju memiliki mesin peka sebanyak 2 unit dan mesin polister sebanyak 1 unit.

Pengukuran di Industri Penggilingan Padi Dwi Tunggal dilakukan pada saat hari cerah dan pencahayaan yang cukup, ruangan produksi terbuka. Pengukuran di Industri Penggilingan Padi Tri Manunggal dilakukan pada saat hari cerah dan 
pencahayaan yang cukup, ruangan produksi terbuka. Pengukuran di Industri Penggilingan Padi Rukun Tani Maju dilakukan pada saat hari cerah dan pencahayaan kurang, ruangan produksi tertutup.

Tabel 1.1 : Hasil Pengukuran Intensitas Suara Di Industri Penggilingan Padi

\begin{tabular}{ccccc}
\hline No & Lokasi & $\begin{array}{c}\text { Titik } \\
\text { Pengukuran }\end{array}$ & $\begin{array}{c}\text { Hasil } \\
\text { Pengukuran } \\
(\mathrm{dBA})\end{array}$ & Ket \\
\hline \multirow{2}{*}{1} & $\mathrm{~A}$ & $\mathrm{~A}_{1}$ & 87.24 & $\mathrm{TMS}$ \\
& & $\mathrm{A}_{2}$ & 91.6 & $\mathrm{TMS}$ \\
& & $\mathrm{A}_{3}$ & 84.99 & $\mathrm{MS}$ \\
\hline \multirow{2}{*}{2} & $\mathrm{~B}$ & $\mathrm{~B}_{1}$ & 57.42 & $\mathrm{MS}$ \\
& & $\mathrm{B}_{2}$ & 84.11 & $\mathrm{MS}$ \\
& & $\mathrm{B}_{3}$ & 78.76 & $\mathrm{MS}$ \\
& & $\mathrm{B}_{4}$ & 85.62 & $\mathrm{TMS}$ \\
\hline \multirow{2}{*}{3} & $\mathrm{C}$ & $\mathrm{C}_{1}$ & 92.17 & $\mathrm{TMS}$ \\
& & $\mathrm{C}_{2}$ & 86.22 & $\mathrm{TMS}$ \\
& & $\mathrm{C}_{3}$ & 84.42 & $\mathrm{MS}$ \\
\hline
\end{tabular}

Kepmenkes No. 1405/MENKES/SK/2002 tentang persyaratan kesehatan lingkungan kerja perkantoran dan industri menyebutkan bahwa tingkat kebisingan di ruang kerja maksimal $85 \mathrm{dBA}$ sedangkan hasil pengukuran pada 3 lokasi penelitian diketahui terdapat 5 titikyang tidak memenuhi syarat $(>\mathrm{NAB}=$ 85 dBA ). Hal ini disebabkan karena :

1. Titik A1 dan titik A2 merupakan mesin penggilingan yang sudah lama yaitu berumur sekitar 30 tahun dan belum pernah diganti.

2. Industri Penggilingan Padi B berada di dekat jalan raya dan titik B4 terletak di dekat pintu yang langsung menghadap jalan raya sehingga suara yang dihasilkanpada titik tersebut lebih keras.

3. Titik $\mathrm{C} 1$ dan $\mathrm{C} 2$ berada di ruang produksi yang tertutup dan hanya terdapat satu pintu sehingga menyebabkan suara mesin penggilingan yang dihasilkan menggema dan intensitas suaranya keras.

Sementara 5 titik yang lain memenuhi syarat karena :

1. Titik A3 merupakan tempat yang digunakan untuk penimbangan dan pengepakan beras dan Industri Penggilingan Padi A letaknya jauh dari jalan raya sehingga intensitas suara yang dihasilkan kecil.

2. Titik B1 merupakan pengukuran yang dilakukan sebelum aktivitas di ruang produksi, titik B2 dan B3 merupakan mesin yang masih baru dan dilakukan perawatan secara rutin sehingga intensitas suara yang dihasilkan tidak keras.

3. Titik C3 merupakan tempat yang digunakan untuk penimbangan dan pengepakan beras sehingga suara yang dihasilkan tidak melebihi NAB yang ditentukan (85 dBA).

Standar yang digunakan yaitu Peraturan Menteri

Tenaga Kerja Nomor 13 Tahun 2011.

Pengamatan yang dilakukan di Industri

Penggilingan Padi Dwi Tunggal, Tri Manunggal dan
Rukun Tani Maju jenis alat pelindung diri yang berupa alat pelindung telinga seperti ear muff atau earplug tidak disediakan.

A. M. Sugeng Budiono (2009, h. 33) menjelaskan bahwa pengaruh kebisingan terhadap kesehatan adalah mengurangi kenyamanan, mengganggu komunikasi, mengurangi konsentrasi, menurunkan daya dengar atau tuli. Berdasarkan hasil kuesioner yang dilakukan pada 8 karyawan didapatkan pada lokasi A terdapat 4 keluhan yang dirasakan yaitu berupa telinga berdenging terdapat 2 keluhan dan pusing/sakit kepala terdapat 2 keluhan, pada lokasi B terdapat 14 keluhan yang dirasakan karyawan berupa telinga berdenging terdapat 2, percakapan diulang terdapat 1, gangguan komunikasi terdapat 8 dan keluhan pusing/sakit kepala terdapat 3, pada lokasi C terdapat 4 keluhan yang dirasakan karyawan yaitu berupa telinga berdenging terdapat 3 , keluhan pusing/sakit kepala terdapat 1. Gangguan pendengaran berupa telinga berdenging lebih banyak karena waktu kerja karyawan lebih lama di ruang produksi sehingga lebih besar resiko terkena paparan dari sumber bising yang terus-menerus yaitu mesin penggilingan, dan jarak karyawan dengan sumber bising sangat dekat yaitu $0,5 \mathrm{~m}$ sehingga karyawan mengalami telinga yang berdenging lebih sering.

Hasil uji statistik menggunakan korelasi range spearman'sdiperoleh hasil $\mathrm{p}=0,223>\alpha(0,05)$, artinya tidak ada hubungan antara intensitas suara mesinpenggilingan padi dengan keluhan gangguan pendengaran pekerja di Desa Kuripan Kecamatan Kesugihan Kabupaten Cilacap.

\section{IV.KESIMPULAN DAN SARAN}

Jumlah mesin penggilingan padi di 3 lokasi berjumlah 11 unit dengan pembagian 4 unit di Industri Penggilingan Padi Dwi Tunggal, 4 unit di Industri Penggilingan Padi Tri Manunggal, 3 unit di Industri Penggilingan Padi Rukun Tani Maju. Hasil pengukuran intensitas suara pada mesin produksi di 3 lokasi penggilingan padi berkisar antara ( 78.76 $92.17 \mathrm{dBA}$ ). Hasil pengukuran intensitas suara pada tempat kerja di 3 lokasi penggilingan padi berkisar antara (57.42 - $92.17 \mathrm{dBA})$. Jenis keluhan yang dialami pekerja pada 3 lokasi penggilingan padi yaitu berupa telinga berdenging, percakapan diulang, gangguan komunikasi dan keluhan pusing/sakit kepala. Hasil uji statistik menggunakan korelasi range spearman's diperoleh hasil $\mathrm{p}=0,223>\alpha(0,05)$, artinya tidak ada hubungan antara intensitas suara mesin penggilingan padi dengan keluhan gangguan pendengaran pekerja di Desa Kuripan Kecamatan

\section{DAFTAR PUSTAKA}

Anis, 2005, Seri Kesehatan Umum Penyakit Akibat Kerja, Jakarta :Elex Media Komputindo

Budiono, Sugeng A.M, 2009, Bunga Rampai Hiperkes dan KK, Semarang : UNDIP 
Cahyono, T, 2012. Pedoman Penulisan Proposal Penelitian dan KaryaTulis Ilmiah/Skripsi (Edisi Revisi Kedua), Kementrian Kesehatan RI Politeknik Kesehatan Kemenkes Semarang Jurusan Kesehatan Lingkungan Purwokerto

Departemen Kesehatan RI, 1990, Upaya Kesehatan Kerja Sektor Informal Di Indonesia, Jakarta : Depkes RI

Keputusan Menteri Tenaga Kerja No 51/Men/1999
L. Meily Kurniawidjaja, 2010, Teori dan Aplikasi Kesehatan Kerja, Jakarta :Penerbit Universitas Indonesia.

Peraturan Menteri Tenaga Kerja dan Transmigrasi No. 01/1961

Ramlan, D, MaisyeMarlyn Kuhu, 2014, Petunjuk Praktis Penulisan Penelitian Eksplanatif, Purwokerto: UPT Percetakan dan Penerbitan Universitas 